\title{
Deep Thiopental Anesthesia Alters Steady- State Glucose Homeostasis but Not the Neurochemical Profile of Rat Cortex
}

\author{
Hongxia Lei, ${ }^{1,2 \star}$ Joao M.N. Duarte, ${ }^{1,3}$ Vladimir Mlynarik, ${ }^{1}$ Agathe Python, ${ }^{1,4}$ \\ and Rolf Gruetter ${ }^{1,2,4}$ \\ ${ }^{1}$ Laboratory of functional and metabolic imaging (LIFMET), Institute of the Physics of Biological Systems, \\ Ecole Polytechnique Fédérale de Lausanne, Lausanne, Switzerland \\ ${ }^{2}$ Department of Radiology, University of Lausanne, Lausanne, Switzerland \\ ${ }^{3}$ Departments of Medicine and Biology, University of Lausanne, Lausanne, Switzerland \\ ${ }^{4}$ Department of Radiology, University of Geneva, Geneva, Switzerland
}

Barbiturates are regularly used as an anesthetic for animal experimentation and clinical procedures and are frequently provided with solubilizing compounds, such as ethanol and propylene glycol, which have been reported to affect brain function and, in the case of ${ }^{1} \mathrm{H}$ NMR experiments, originate undesired resonances in spectra affecting the quantification. As an alternative, thiopental can be administrated without any solubilizing agents. The aim of the study was to investigate the effect of deep thiopental anesthesia on the neurochemical profile consisting of 19 metabolites and on glucose transport kinetics in vivo in rat cortex compared with $\alpha$ chloralose using localized ${ }^{1} \mathrm{H}$ NMR spectroscopy. Thiopental was devoid of effects on the neurochemical profile, except for the elevated glucose at a given plasma glucose level resulting from thiopental-induced depression of glucose consumption at isoelectrical condition. Over the entire range of plasma glucose levels, steadystate glucose concentrations were increased on average by $48 \% \pm 8 \%$, implying that an effect of deep thiopental anesthesia on the transport rate relative to cerebral glucose consumption ratio was increased by $47 \% \pm 8 \%$ compared with light $\alpha$-chloraloseanesthetized rats. We conclude that the thiopentalinduced isoelectrical condition in rat cortex significantly affected glucose contents by depressing brain metabolism, which remained substantial at isoelectricity. ๑ 2009 Wiley-Liss, Inc.

Key words: ${ }^{1} \mathrm{H}$ MRS; neurochemical profile; thiopental; glucose; glucose transport

Barbiturates are widely used as anesthetics and to some extent are applied as protective agents, such as during and after anoxic events (Yatsu et al., 1972; Steen et al., 1978; Amakawa et al., 1996; Kobayashi et al., 2007) or traumatic brain injuries (Huynh et al., 2009, and references therein), which can be ascribed to their function as central nervous system depressants, mainly by binding $\gamma$-aminobutyric acid type $\mathrm{A}\left(\mathrm{GABA}_{\mathrm{A}}\right)$ receptors and possibly interacting with glutamate receptors (Marszalec and Narahashi, 1993). Additionally, barbiturates have been shown to depress energy metabolism by, e.g., inhibiting the oxidation of NADH in the respiratory chain (Aldridge and Parker, 1960; Chance et al., 1963), glucose transport at the blood-brain barrier (BBB; Haspel et al., 1999), and cerebral glucose utilization (Strang and Bachelard, 1973; Sokoloff et al., 1977). Therefore, investigation of the effect of barbiturates in vivo in animal models might potentially help in understanding their particular pharmacological roles.

Magnetic resonance spectroscopy (MRS) is a powerful investigational tool that has been widely applied to study brain metabolism noninvasively (see, e.g., de Graaf et al., 2003; Gruetter et al., 2003; Morris and Bachelard, 2003; Jansen et al., 2006; Zhu et al., 2009, and references therein). For instance, the effect of barbiturates on tricarboxylic acid cycle flux; aspartate, glutamate, and glutamine metabolism; and glucose transport kinetics has been assessed via ${ }^{13} \mathrm{C}$ MRS (Choi et al., 2002). However, in that study, a relatively large volume of interest containing a mixture of gray matter and white matter was used. It is well established that there are regional differences in the cerebral metabolic rate of glucose, $\mathrm{CMR}_{\text {glc }}$ (Hawkins et al., 1983). Recent studies of glucose transport kinetics on humans suggested slightly lower glucose content in gray than in white mat-

Contract grant sponsor: Centre d'Imagerie BioMédicale (CIBM) of the UNIL, UNIGE, HUG, CHUV and EPFL; Contract grant sponsor: Leenaards and Jeantet Foundations; Contract grant sponsor: SNSF; Contract grant number: 3100A0-116220.

${ }^{\star}$ Correspondence to: Hongxia Lei, PhD, Laboratory of Functional and Metabolic Imaging, Institute of the Physics of Biological Systems, Ecole Polytechnique Fédérale de Lausanne, CH-1015 Lausanne, Switzerland. E-mail: hongxia.lei@epfl.ch

Received 23 March 2009; Revised 19 May 2009; Accepted 25 June 2009

Published online 10 September 2009 in Wiley InterScience (www. interscience.wiley.com). DOI: 10.1002/jnr.22212 
ter (de Graaf et al., 2001). Consequently, the apparent glucose transport kinetic, mainly the maximum glucose transport rate $\left(\mathrm{T}_{\max }\right)$ to $\mathrm{CMR}_{\text {glc }}$ ratio in gray matter, was found to be lower than that in white matter (de Graaf et al., 2001). Study of metabolism over specific brain regions, such as cortex, would eventually minimize possible contamination from other brain regions.

Although most MR studies addressing brain glucose content have used ${ }^{13} \mathrm{C}$ MRS, ${ }^{1} \mathrm{H}$ MRS has higher sensitivity and has recently shown the capability of measuring metabolites, including glucose (Glc), from a relative small volume in rodents (Tkáč et al., 2007). Furthermore, a neurochemical profile consisting of more than 18 metabolites can be measured (Pfeuffer et al., 1999; Mlynárik et al., 2006; Tkáč et al., 2007). However, barbiturates such as pentobarbital available for clinical purposes contain compounds such as ethanol and propylene glycol, which are detectable in acquired ${ }^{1} \mathrm{H}-$ MR spectra (Iltis et al., 2008, and references therein). As a consequence, additional efforts are required to minimize the effects on quantification. In addition, the effect of barbiturates may be differentially affected by the aforementioned solubilizing agents. Ethanol and propylene glycol likely enter the brain and have been reported to affect glucose transport and $\mathrm{CMR}_{\text {glc }}$ in rat cortex (Singh et al., 1993; Handa et al., 2000) as well as osmotic opening of the BBB (Rapoport et al., 1972; Demey et al., 1988). The aim of the present study was to investigate the effect of deep anesthesia with thiopental prepared in saline solution on glucose transport kinetics and the neurochemical profile in rat cortex via ${ }^{1} \mathrm{H}$ MR spectroscopy.

\section{MATERIALS AND METHODS}

\section{Animal Preparation and Handling}

All procedures involving animals were performed according to the federal law and approved by the local ethics committee. Eighteen male Sprague Dawley rats (260-350 g; Charles River, France) were intubated under 2\% isoflurane (Attane; Minrad) anesthesia in $\mathrm{O}_{2}$ gas and mechanically ventilated thereafter (MRI-1 ventilator; CWE Inc.). Immediately after both femoral veins and one femoral artery had been cannulated, anesthesia of animals was switched from isoflurane to i.v. infusion of either light $\alpha$-chloralose (Acros Oraganics, Geel, Belgium) or deep thiopental anesthesia (distributed by Ospedalia AG, Hunenberg, Switzerland). To mimic very light anesthesia and allow comparison with previous in vivo MR studies (Choi et al., 2001), an identical protocol was used in eight rats as follows: a $40 \mathrm{mg} / \mathrm{kg}$ initial bolus followed by $\sim 27 \mathrm{mg} / \mathrm{kg} / \mathrm{hr}$ continuous rate infusion. Deep thiopental anesthesia was achieved in 10 animals by administering a $50 \mathrm{mg} / \mathrm{kg}$ bolus followed immediately by a continuous infusion at $70-80 \mathrm{mg} / \mathrm{kg} / \mathrm{hr}$, which induced isoelectricity (Mather et al., 2000; Michenfelder, 2002), and this was confirmed in three animals on the bench by electroencephalographic measurements (data not shown).

Rats were stereotaxically fixed with two ear pieces and a bite bar in a home-made holder and placed at the isocenter of the magnet. Throughout the entire experiment, the animal was monitored for breathing, temperature, and blood pressure $(\sim 90-150 \mathrm{mmHg})$ with an MR-compatible monitor system (model 1025; SA Instruments, Stony Brook, NY), and rectal temperature was maintained at $38.0^{\circ} \mathrm{C}$ by circulating warm water. Blood gases were maintained within normal physiological conditions ( $\mathrm{pH} \sim 7.4, \mathrm{PaCO}_{2} \sim 40 \mathrm{mmHg}$ ) throughout the studies based on the concomitant arterial blood measurement using a nearby analyzer (AVL Compact 3; Roche Diagnostic AG, Basel, Switzerland). Once $\mathrm{pH}$ or $\mathrm{PaCO}_{2}$ fell out of normal ranges, such as $7.2-7.5$ or $35-45 \mathrm{mmHg}$, respectively, the acquired data were excluded for further analysis. To minimize the residual effects of isoflurane anesthetic from the preparation, all quantitative data were acquired $1 \mathrm{hr}$ after switching anesthesia.

\section{${ }^{1} \mathrm{H}$ MRS Methods}

All MR experiments were performed in a $9.4-\mathrm{T} / 31-\mathrm{cm}$ horizontal magnet (Magnex Scientific, United Kingdom). The magnet was equipped with an actively shielded $12-\mathrm{cm}$-diameter gradient $(400 \mathrm{mT} / \mathrm{m}$ in $120 \mu \mathrm{sec}$; Magnex Scientific). The magnet was interfaced to a VNMRJ console (Varian Inc., Palo Alto, CA). Eddy currents were minimized to be less than $0.01 \%$ by time-dependent quantitative eddy current field mapping (Terpstra et al., 1998). A home-made quadrature ${ }^{1} \mathrm{H}$ radiofrequency (RF) coil with two geometrically decoupled 16-mm (inner diameter) loops resonating at $400 \mathrm{MHz}$ was used as RF transceiver (Adriany and Gruetter, 1997).

Multislice fast spin echo images with $\mathrm{T}_{2}$-weigthed $\mathrm{pa}$ rameters $(\mathrm{TE} / \mathrm{TR}=50 / 5,000 \mathrm{msec})$ were acquired as anatomical images to locate the volume of interest (VOI) of 30$37 \mu \mathrm{l}$ in the cerebral cortex. After automatic adjustment of field inhomogeneities (Gruetter and Tkáč, 2000), the resulting water line width was $13-17 \mathrm{~Hz}$. Localized ${ }^{1} \mathrm{H}$ MRS was performed with SPECIAL (Mlynárik et al., 2006) with echo time of $2.8 \mathrm{msec}$ and repetition time of $4 \mathrm{sec}$, and 160-320 scans were averaged.

\section{Quantification of ${ }^{1} \mathrm{H}-\mathrm{MR}$ Spectra}

In vivo ${ }^{1} \mathrm{H}$ MR spectra were processed as previously described (Tkáč et al., 2007), frequency drift corrected, summed, and eddy-current compensated using the water signal from the same VOI. Thereafter, absolute quantification was obtained by using LCModel (Provencher, 1993), assuming $80 \%$ brain water content (Tkáć et al., 2003). In this study, all metabolites except macromolecules (Mac) in the basic set of LCModel were simulated, i.e., alanine (Ala), ascorbate (Asc), aspartate (Asp), creatine (Cr), myo-inositol (myo-Ins), $\gamma$-aminobutryric acid (GABA), Glc, glutamine (Gln), glutamate (Glu), glycine (Gly), glycerophoshocholine (GPC), glutathione (GSH), lactate (Lac), N-acetyl-aspartate (NAA), Nacetyl-aspartyl-glutamate (NAAG), phosphocholine (PCho), phosphocreatine (PCr), phosphorylethanolamine (PE), scylloinositol (Scyllo), and taurine (tau). Most of the metabolites were quantified with Cramer-Rao lower bounds (CRLB) $<35 \%$, which corresponds to errors in metabolite concentrations of less than $0.5 \mu \mathrm{mol} / \mathrm{g}$. Measurements with CRLB $>50 \%$ were considered not detectable, such as Scyllo. Because 
GPC and PCho were not well-separated at 9.4 T (Tkáč et al., 1999), the sum of GPC and PCho was reported. Additionally, summed metabolites including $\mathrm{PCr}+\mathrm{Cr}$, NAA + NAAG, and Glu + Gln, were evaluated for further comparison with previous studies.

\section{Determination of Glucose Transport Kinetics}

To evaluate glucose transport kinetics from the relationship between brain and plasma glucose as in previous studies (Gruetter et al., 1998a; Lei and Gruetter, 2006), cortical glucose content was measured by localized ${ }^{1} \mathrm{H}$ MRS when steady-state glycemia was maintained for at least $20 \mathrm{~min}$ by adjusting the infusion rate of $20 \%$ (w/v) D-glucose (SigmaAldrich, Switzerland) solution, based on the concomitant measured plasma glucose using a nearby glucose analyzer (GM7 Micro-Stat; Analox Instruments, United Kingdom). To increase the precision of cortex glucose measurement at plasma glucose below $10 \mathrm{mM}$, spectra were acquired with an increased number of scans of 320 .

It has been well established that apparent kinetic parameters of glucose transport at $\mathrm{BBB}$ can be estimated from the relationship between brain glucose and plasma glucose at steady state (Lund-Andersen, 1979; Gruetter et al., 1992, 1998b; Barros et al., 2007). To compare with previous in vivo studies, the reversible Michaelis-Menten model was used to obtain kinetic parameters using the following equation (Gruetter et al., 1998b):

$$
\mathrm{G}_{\text {cortex }}=\mathrm{V}_{\mathrm{d}} \times \frac{\left(\frac{\mathrm{T}_{\max }}{\mathrm{CMR}_{\mathrm{glc}}}-1\right) \times \mathrm{G}_{\text {plasma }}-\mathrm{K}_{\mathrm{t}}}{\left(\frac{\mathrm{T}_{\max }}{\mathrm{CMR}_{\mathrm{glc}}}+1\right)},
$$

where $G$ represents the glucose concentrations in cortex $(\mu \mathrm{mol} / \mathrm{g})$ or in plasma $(\mathrm{mM}), \mathrm{V}_{\mathrm{d}}=0.77 \mathrm{ml} / \mathrm{g}$ is the physical distribution space of water in the cortex, $\mathrm{T}_{\max }$ is the apparent maximum transport rate, $\mathrm{CMR}_{\mathrm{glc}}$ is the cerebral glucose metabolic rate, and $\mathrm{K}_{\mathrm{t}}$ is the apparent Michaelis-Menten constant. Fitting of Equation 1 to the measured $G_{\text {cortex }}$ as a function of $\mathrm{G}_{\text {plasma }}$ was performed in GraphPad Prism 5 (GraphPad Software Inc., San Diego, CA).

\section{Statistical Analysis}

All data are presented as mean \pm SEM unless otherwise stated. The experimental errors of calculated values, such as change in the apparent transport ratio $\mathrm{T}_{\max } / \mathrm{CMR}_{\mathrm{glc}}$ under deep thiopental anesthesia compared with that under light $\alpha$ chloralose anesthesia was evaluated based on the law of propagation of errors.

The neurochemical profile measured under both anesthetic regimes was compared by unpaired Student's $t$-test. To correct for multiple comparisons in the neurochemical profiles, the threshold for significant difference was restricted to $P=0.01$, whereas $P=0.0027$ was the threshold after Bonferroni correction for comparing the 19 constituents of the neurochemical profile. The resulting parameters of glucose transport, i.e., $\mathrm{T}_{\max } / \mathrm{CMR}_{\mathrm{glc}}$ and $\mathrm{K}_{\mathrm{t}}$ obtained from of the fit of Equation 1, were compared between anesthetic regimes using the paradigm for comparing models, followed by the
F test, provided in GraphPad Prism 5. The difference was considered different at $P=0.05$.

\section{RESULTS \\ ${ }^{1}$ H MR Spectroscopy of Cortex}

The adjustment of field inhomogeneities resulted in excellent metabolite line widths of $9 \pm 1 \mathrm{~Hz}$, and water was noticeably and consistently suppressed below the level of NAA. Localized ${ }^{1} \mathrm{H}$ spectra with signal-tonoise ratios of $21 \pm 3$ and $31 \pm 2$ were acquired under $\alpha$-chloralose and thiopental anesthesia, respectively. Consequently, LCModel analysis of such data allowed analyzing 21 individual metabolites (Fig. 1).

Spectra acquired at the two different anesthetic regimes did not exhibit apparent differences, as shown in Figure 2. Note that, at a similar glycemic level of $\sim 15$ $\mathrm{mM}$, the Glc resonance at 5.25 ppm was clearly visible under both anesthesia conditions (Fig. 2B,C) and was higher with deep thiopental anesthesia (Fig. 2C). Subtracting the spectrum acquired under $\alpha$-chloralose (Fig. 2B) from the spectrum obtained under deep thiopental (Fig. 2C) resulted in residuals (Fig. 2D) most of which are explained by difference in glucose content compared with the glucose pattern in the range of 3-4.2 ppm (Fig. $2 \mathrm{E})$, which is overlapped by other metabolites in Figures 1 and $2 \mathrm{~B}, \mathrm{C}$.

\section{Neurochemical Profiles of Cortex}

LCModel quantification provided the neurochemical profiles consisting of 19 metabolites (Fig. 3). To assess directly the effect of deep thiopental anesthesia on neurochemical profile, the measurements from the two anesthetic groups were compared at similar plasma glucose levels, i.e., when plasma glucose was between 10 and $15 \mathrm{mM}$. The neurochemical profiles were not significantly different except for cortical Glc content with $P=0.0024$ (Fig. 3), as judged from both the restricted threshold and the threshold with Bonferroni correction (see Materials and Methods). Further two-way ANOVA analysis in categories of both anesthetic regimes $(\alpha-$ chloralose vs. thiopental) and plasma glucose on the measurements grouped into respective plasma glucose ranges of $5-10[8.2 \pm 0.8(4)$ vs. $7.6 \pm 0.9(25)], 10-20$ $[16.3 \pm 0.7(7)$ vs. $15.4 \pm 0.6(12)]$, and 20-30 [24.4 \pm $1.0(6)$ vs. $23.2 \pm 0.8(4)] \mathrm{mM}$ showed a significant increase in cortical glucose concentration with thiopental anesthesia, with $P<0.01$ and $P<0.001$, respectively.

\section{Glucose Transport Kinetics in Cortex}

When plotting tissue glucose as a function of plasma glucose concentration, a linear relationship was observed over the entire range of plasma glucose measured with both anesthetic regimes (Fig. 4). In addition, cortical glucose under deep thiopental anesthesia (triangles in Fig. 4) was clearly higher than glucose measured under $\alpha$-chloralose anesthesia (circles in Figure 4). When averaged at three different plasma glucose ranges, i.e., 5-10, 10-20, and 20-30 mM, cortical glucose was 


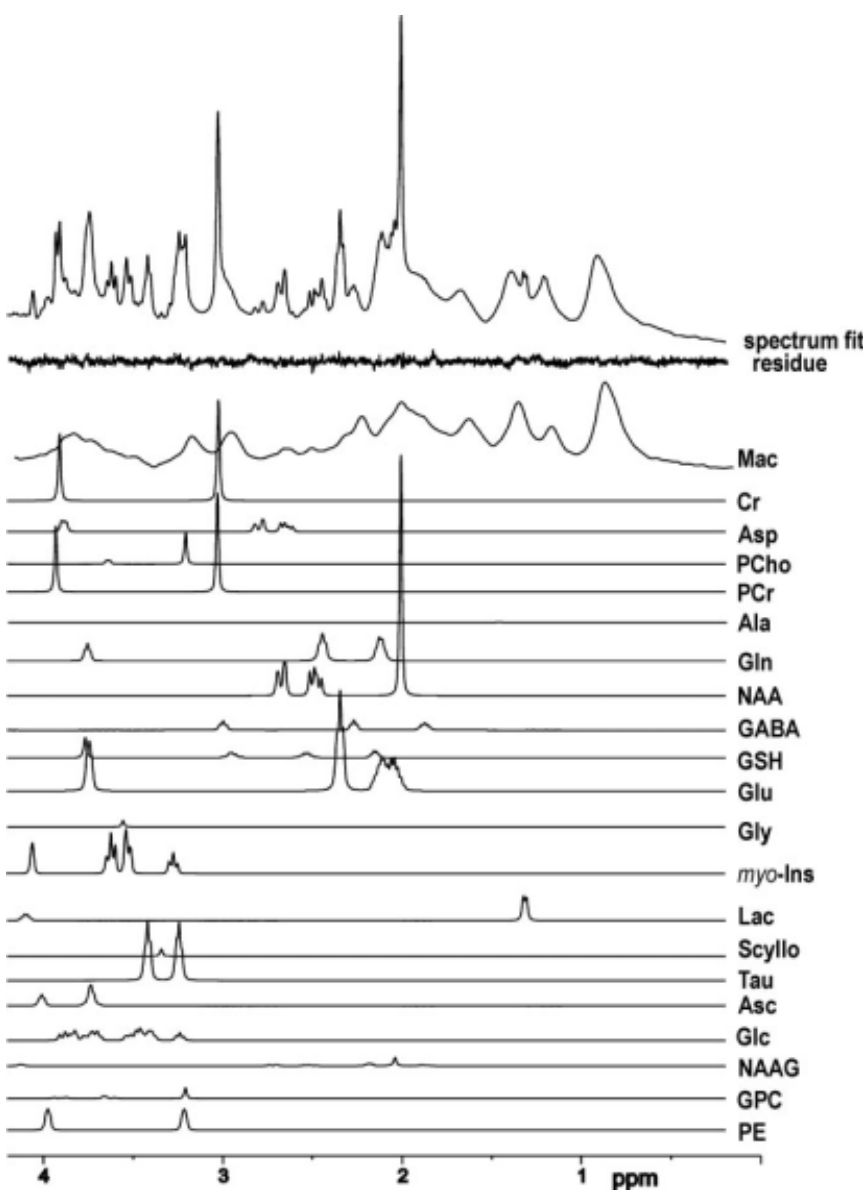

Fig. 1. Typical example of LCModel analysis of one localized spectrum at $9.4 \mathrm{~T}$. The top trace is the resulting spectrum fit followed by the fit residual and the 21 individual components. Ala, alanine; Asc, ascorbate; Asp, aspartate; Cr, creatine; myo-Ins, myo-inositol; GABA, $\gamma$-aminobutryric acid; Glc, glucose; Gln, glutamine; Glu, glutamate; Gly, glycine; GPC, glycerophosphocholine; GSH, glutathione; Lac, lactate; Mac, macromolecule; NAA, N-acetyl-aspartate, NAAG, N-acetyl-aspartyl-glutamate; PCho, phosphocholine; PCr, phosphocreatine; PE, phosphorylethanolamine; Scyllo, scyllo-inositol; Tau, taurine.

increased overall by $48 \% \pm 8 \%$. Fitting the data with Equation 1 resulted in an apparent maximum transport rate, $\mathrm{T}_{\max } / \mathrm{CMR}_{\mathrm{glc}}$, of $2.8 \pm 0.2$ and an apparent Michaelis-Menten constant, $\mathrm{K}_{\mathrm{t}}$, of $2.8 \pm 1.1 \mathrm{mM}$ under deep thiopental anesthesia and $\mathrm{T}_{\max } / \mathrm{CMR}_{\text {glc }}$ of $1.9 \pm$ 0.1 and $\mathrm{K}_{\mathrm{t}}$ of $2.5 \pm 1.2 \mathrm{mM}$ under light $\alpha$-chloralose anesthesia. Between the two anesthetic regimes, $\mathrm{T}_{\max } /$ $\mathrm{CMR}_{\text {glc }}$ was found to be different $(P<0.0001, \mathrm{~F}=$ $19.41)$ but not $\mathrm{K}_{\mathrm{t}}(P=0.86, \mathrm{~F}=0.03)$. Note that, even under isoelectrical conditions, cortex glucose content was significantly lower than the corresponding plasma glucose concentration.

\section{DISCUSSION}

The present study shows for the first time that deep thiopental anesthesia has minimal effect on the
(A)

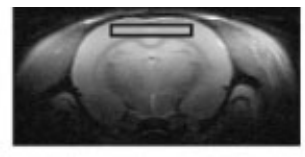

(B)

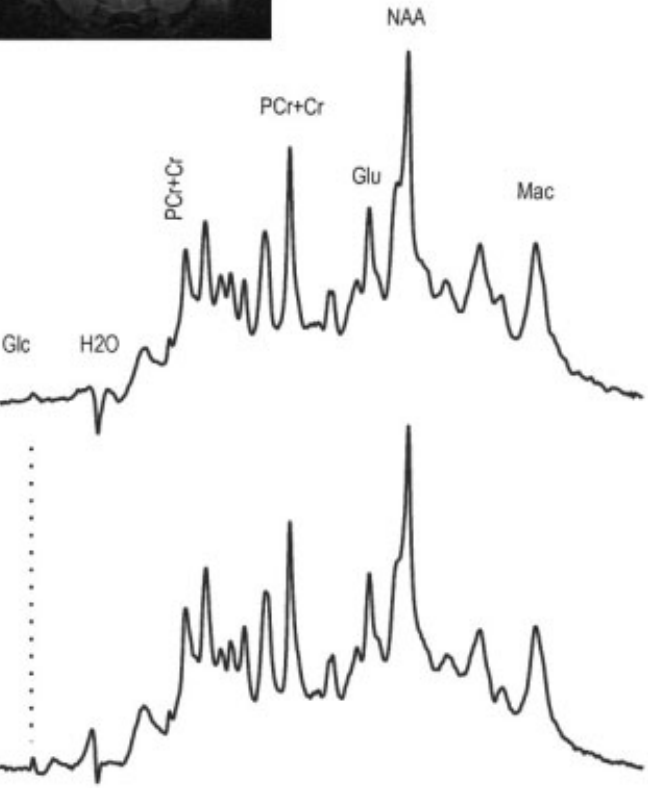

(D)

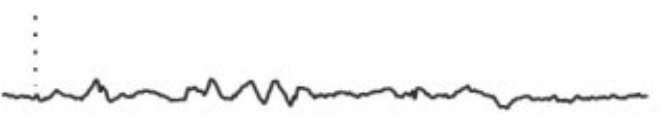

(E)
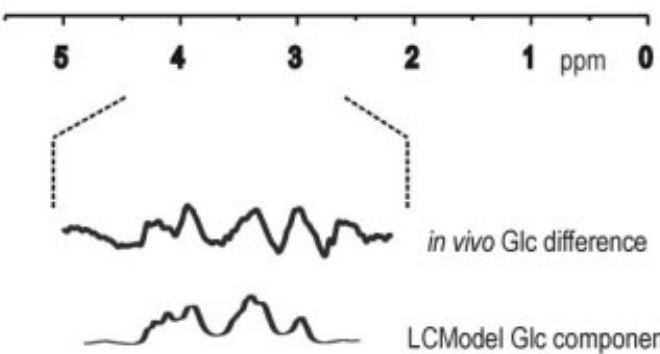

LCModel Glc component (as Figure 1)

Fig. 2. Typical ${ }^{1} \mathrm{H}$ MR spectra were acquired in one of each anesthetized animal when plasma glucose was $\sim 15 \mathrm{mM}$ under both light $\alpha$-chloralose $(\mathbf{B})$ and deep thiopental $(\mathbf{C})$ from cortex, indicated as in the MR anatomical image (A; boxed area). The resonance of glucose at $5.25 \mathrm{ppm}$ was visible in both spectra and is indicated with "Glc" and dotted lines. For the difference of spectra B and C, an identical line width of total creatine $(\mathrm{PCr}+\mathrm{Cr})$ was achieved by applying Gaussian apodization $(\mathrm{gf}=0.18 \mathrm{sec})$ and line broadening $(8 \mathrm{~Hz}$ for the spectrum in $\mathrm{B}$ and $5 \mathrm{~Hz}$ for that in $\mathrm{C}$ ). $\mathbf{D}$ is the direct result of subtracting the spectrum in $\mathrm{B}$ from that in $\mathrm{C}$ with no further processing. The difference (D) is apparently discriminated mainly by glucose signals, as illustrated in $\mathbf{E}$, in which the selected region from $\mathrm{D}$ (dashed lines) was amplified (top trace in E), followed by the corresponding Glc fit component (bottom trace in E, as in Fig. 1; see Materials and Methods). Cr, creatine; Glc, glucose; Glu, glutamate; Mac, macromolecule; NAA, N-acetyl-aspartate, $\mathrm{PCr}$, phosphocreatine.

neurochemical profile but substantially increases brain glucose content in rat cortex as measured in vivo by localized ${ }^{1} \mathrm{H}$ MRS. The neurochemical profile measured under light $\alpha$-chloralose in the present study (Fig. 3) 


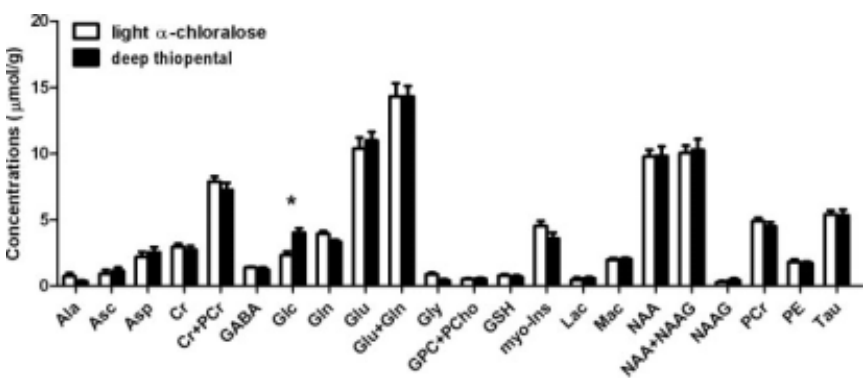

Fig. 3. Neurochemical profile of rat cortex under either light $\alpha$ chloralose $(\sim 27 \mathrm{mg} / \mathrm{kg} / \mathrm{hr}$, open bars) or deep thiopental anesthesia ( $\sim 80 \mathrm{mg} / \mathrm{kg} / \mathrm{hr}$, solid bars) at plasma glucose concentrations ranging from 10 to $15 \mathrm{mM}(11.8 \pm 0.7$ and $12.1 \pm 1.8 \mathrm{mM}$ of plasma glucose for $\alpha$-chloralose and thiopental anesthesia groups, respectively). Error bars represent SEM. ${ }^{\star} P=0.0024$ by unpaired two-tailed Student's $t$-test. In each group, six spectra were selected based on the criteria described in Materials and Methods. Ala, alanine; Asc, ascorbate; Asp, aspartate; Cr, creatine; GABA, $\gamma$-aminobutryric acid; Glc, glucose; Gln, glutamine; Glu, glutamate; Gly, glycine; GPC, glycerophosphocholine; GSH, glutathione; myo-Ins, myo-inositol; Lac, lactate; Mac, macromolecule; NAA, N-acetyl-aspartate, NAAG, $\mathrm{N}$-acetyl-aspartyl-glutamate; PCho, phosphocholine; PCr, phosphocreatine; PE, phosphorylethanolamine; Tau, taurine.

exhibits similar characteristics of cortical tissue, such as Asp, myo-Ins, NAA, and Tau concentrations nearly identical to those from the same strains (Xu et al., 2005). In addition, the measured neurochemical profile under deep thiopental anesthesia extends previous measurements of concentrations of NAA, PCr, Cr, and Lac (Michenfelder, 2002; Iltis et al., 2008) to a significantly larger number of metabolites, such as total choline (GPC + PCho), Ala, Asc, Gln, Glu, GSH, Gly, PE, and Tau. In particular, the unchanged Gln and Glu concentrations in cortex over a wide range of plasma glucose levels suggest a tight regulation of neurotransmitter homeostasis when electrical activity is chemically depressed. The impairment of astrocyte glutamate update observed in vitro (Swanson and Seid, 1998) may be counteracted by reduced glutamate efflux (Pastuszko et al., 1984; Qu et al., 1999). This is in contrast to other isoelectrical conditions, such as hibernation or hypoglycemia, in which substantial decreases in total Glu + Gln have been reported (Henry et al., 2007; Sutherland et al., 2008). This suggests that the control of neurotransmitter homeostasis depends not only on electrical activity but also on the mechanism by which it is altered.

In contrast to all the aforementioned metabolites, cortical glucose content at a given steady-state plasma glucose concentration was increased under deep thiopental anesthesia compared with that under light $\alpha$-chloralose anesthesia (Figs. 2, 3). It has been well established that steady-state glucose content in brain reflects the capacity of the BBB to transport glucose relative to glucose consumption, expressed by the ratio $\mathrm{T}_{\max } / \mathrm{CMR}_{\mathrm{glc}}$ (de Graaf et al., 2001; Choi et al., 2002; Lei and Gruetter, 2006). It is of interest to note that the linear rela-

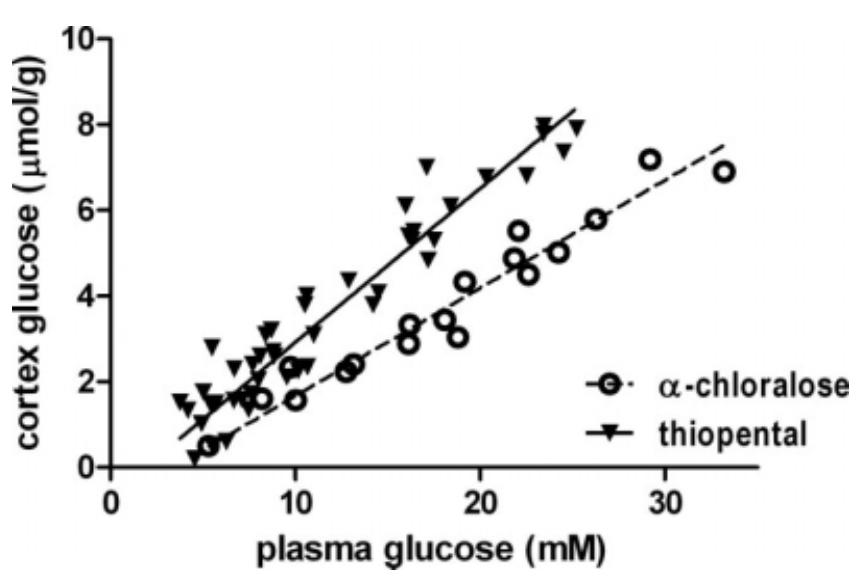

Fig. 4. Cortex glucose contents as a function of plasma glucose concentrations at steady state under $\alpha$-chloralose (circles) and deep thiopental (triangles) anesthesia. The results of the fit of Equation 1 are shown as the dashed line and the solid line for $\alpha$-chloralose and deep thiopental anesthesia, respectively.

tionship between cortex and plasma glucose from $4 \mathrm{mM}$ up to $35 \mathrm{mM}$ (Fig. 4) is a characteristic of the reversible Michaelis-Menten kinetics model (Gruetter et al., 1998b) as well as the gliovascular glucose transport model (Barros et al., 2007), which has been observed in a number of studies across species or under different states of electrical activities (Gruetter et al., 1998b; Choi et al., 2001, 2002; de Graaf et al., 2001; Lei and Gruetter, 2006). The observed elevated linear relationship under deep thiopental anesthesia (Fig. 4) mostly reflects changes in $\mathrm{T}_{\max } / \mathrm{CMR}_{\mathrm{glc}}$ regardless of the specific kinetic model used. Conversely, an increase of $\mathrm{T}_{\max } /$ $\mathrm{CMR}_{\mathrm{glc}}$ by $47 \% \pm 8 \%$ would explain the increase of glucose contents observed in the present study. Additionally, the resulting apparent Michaelis-Menten constants, $\mathrm{K}_{\mathrm{t}}$, with both anesthetic regimes did not present any significant difference and was nearly identical to previously reported values for rodents (Gruetter et al., 1998b; Choi et al., 2001).

When assuming that deep thiopental anesthesia solely affects $\mathrm{CMR}_{\mathrm{glc}}$, the $47 \%$ increase of $\mathrm{T}_{\max } / \mathrm{CMR}_{\mathrm{glc}}$ amounts to a $32 \%$ reduction in $\mathrm{CMR}_{\text {glc }}$, which is slightly lower than the previously reported $45 \%$ reduction in cortex under the same condition (Wechsler et al., 1950; Sokoloff et al., 1977). The extent to which minor reductions in $\mathrm{T}_{\max }$ on the order of $20 \%$ might have occurred in vivo, as has been reported in vitro (Haspel et al., 1999), remains to be determined. Regardless of possible alterations in $T_{\max }$, the fact that brain glucose content was clearly increased with deep thiopental anesthesia (Figs. 2-4) implies that decreases in transport capacity were smaller than the decreases in $\mathrm{CMR}_{\mathrm{glc}}$, insofar as the steady-state glucose content is a sensitive indicator of $\mathrm{T}_{\max } / \mathrm{CMR}_{\mathrm{glc}}$ (Choi et al., 2002; Lei and Gruetter, 2006; Barros et al., 2007).

Although we observed a significant increase in brain glucose content, a substantial glucose concentration 
gradient across the BBB was maintained at isoelectricity, which implies the presence of significant glucose metabolism at isoelectricity. It is of interest to note that the whole-brain glucose concentration increases under pentobarbital anesthesia (Choi et al., 2002) were nearly twofold higher than the cortical glucose increase measured in the current study (Fig. 4). At present, we cannot preclude that this difference in brain glucose increase reflects either a regional effect of pentobarbital or a stronger effect of pentobarbital per se (Haspel et al., 1999) or is due to regional difference in the relative contribution of the housekeeping energy requirements (Attwell and Laughlin, 2001; Barros et al., 2005). Alternatively, propylene glycol has been shown to affect BBB transport and permeability in a concentration-dependent fashion (Rapoport et al., 1972; Sood et al., 2007), so the extent to which addition of propylene glycol as well as ethanol, which itself has been reported to affect the BBB permeability (Rapoport et al., 1972; Demey et al., 1988), can compound the effect of pentobarbital of brain glucose content remains to be determined. We conclude that deep thiopental anesthesia does not affect the neurochemical profile in rat cortex but leads to increased brain glucose content, implying a reduced glucose metabolic rate that remains substantial at isoelectricial conditions along with possible inhibition of glucose transport.

\section{ACKNOWLEDGMENTS}

The authors thank Hanne Frenkel and Stephane Germaine for excellent technical support.

\section{REFERENCES}

Adriany G, Gruetter R. 1997. A half-volume coil for efficient proton decoupling in humans at 4 Tesla. J Magn Reson 125:178-184.

Aldridge WN, Parker VH. 1960. Barbiturates and oxidative phosphorylation. Biochem J 76:47-56.

Amakawa K, Adachi N, Liu K, Ikemune K, Fujitani T, Arai T. 1996. Effects of pre- and postischemic administration of thiopental on transmitter amino acid release and histologic outcome in gerbils. Anesthesiology 85:1422-1430.

Attwell D, Laughlin SB. 2001. An energy budget for signaling in the grey matter of the brain. J Cereb Blood Flow Metab 21:1133-1145.

Barros LF, Porras OH, Bittner CX. 2005. Why glucose transport in the brain matters for PET. Trends Neurosci 28:117-119.

Barros LF, Bittner CX, Loaiza A, Porras OH. 2007. A quantitative overview of glucose dynamics in the gliovascular unit. Glia 55:1222-1237.

Chance B, Williams GR, Hollunger G. 1963. Inhibition of electron and energy transfer in mitochondria. I. Effects of Amytal, thiopental, rotenone, progesterone, and methylene glycol. J Biol Chem 238:418-431.

Choi IY, Lee SP, Kim SG, Gruetter R. 2001. In vivo measurements of brain glucose transport using the reversible Michaelis-Menten model and simultaneous measurements of cerebral blood flow changes during hypoglycemia. J Cereb Blood Flow Metab 21:653-663.

Choi IY, Lei H, Gruetter R. 2002. Effect of deep pentobarbital anesthesia on neurotransmitter metabolism in vivo: on the correlation of total glucose consumption with glutamatergic action. J Cereb Blood Flow Metab 22:1343-1351.

de Graaf RA, Pan JW, Telang F, Lee JH, Brown P, Novotny EJ, Hetherington HP, Rothman DL. 2001. Differentiation of glucose transport in human brain gray and white matter. J Cereb Blood Flow Metab 21:483-492.

de Graaf RA, Brown PB, Mason GF, Rothman DL, Behar KL. 2003. Detection of $\left[1,6-{ }^{13} \mathrm{C}_{2}\right]$-glucose metabolism in rat brain by in vivo ${ }^{1} \mathrm{H}-\left[{ }^{13} \mathrm{C}\right]-\mathrm{NMR}$ spectroscopy. Magn Reson Med 49:37-46.

Demey HE, Daelemans RA, Verpooten GA, De Broe ME, Van Campenhout CM, Lakiere FV, Schepens PJ, Bossaert LL. 1988. Propylene glycol-induced side effects during intravenous nitroglycerin therapy. Intensive Care Med 14:221-226.

Gruetter R, Tkáč I. 2000. Field mapping without reference scan using asymmetric echo-planar techniques. Magn Reson Med 43:319-323.

Gruetter R, Novotny EJ, Boulware SD, Rothman DL, Mason GF, Shulman GI, Shulman RG, Tamborlane WV. 1992. Direct measurement of brain glucose concentrations in humans by ${ }^{13} \mathrm{C}$ NMR spectroscopy. Proc Natl Acad Sci USA 89:1109-1112.

Gruetter R, Seaquist ER, Kim S, Ugurbil K. 1998a. Localized in vivo

${ }^{13} \mathrm{C}-\mathrm{NMR}$ of glutamate metabolism in the human brain: initial results at 4 tesla. Dev Neurosci 20:380-388.

Gruetter R, Ugurbil K, Seaquist ER. 1998b. Steady-state cerebral glucose concentrations and transport in the human brain. J Neurochem 70:397408.

Gruetter R, Adriany G, Choi IY, Henry PG, Lei H, Oz G. 2003. Localized in vivo ${ }^{13} \mathrm{C}$ NMR spectroscopy of the brain. NMR Biomed 16:313-338.

Handa RK, DeJoseph MR, Singh LD, Hawkins RA, Singh SP. 2000. Glucose transporters and glucose utilization in rat brain after acute ethanol administration. Metab Brain Dis 15:211-222.

Haspel HC, Stephenson KN, Davies-Hill T, El-Barbary A, Lobo JF, Croxen RL, Mougrabi W, Koehler-Stec EM, Fenstermacher JD, Simpson IA. 1999. Effects of barbiturates on facilitative glucose transporters are pharmacologically specific and isoform selective. J Membr Biol 169:45-53.

Hawkins RA, Mans AM, Davis DW, Hibbard LS, Lu DM. 1983. Glucose availability to individual cerebral structures is correlated to glucose metabolism. J Neurochem 40:1013-1018.

Henry PG, Russeth KP, Tkáč I, Drewes LR, Andrews MT, Gruetter R. 2007. Brain energy metabolism and neurotransmission at near-freezing temperatures: in vivo ${ }^{1} \mathrm{H}$ MRS study of a hibernating mammal. J Neurochem 101:1505-1515.

Huynh F, Mabasa VH, Ensom MH. 2009. A critical review: does thiopental continuous infusion warrant therapeutic drug monitoring in the critical care population? Ther Drug Monit 31:153-169.

Iltis I, Marjanska M, Du F, Koski DM, Zhu XH, Ugurbil K, Chen W, Henry PG. 2008. ${ }^{1} \mathrm{H}$ MRS in the rat brain under pentobarbital anesthesia: accurate quantification of in vivo spectra in the presence of propylene glycol. Magn Reson Med 59:631-635.

Jansen JF, Backes WH, Nicolay K, Kooi ME. 2006. ${ }^{1} \mathrm{H}$ MR spectroscopy of the brain: absolute quantification of metabolites. Radiology 240:318-332.

Kobayashi M, Takeda Y, Taninishi H, Takata K, Aoe H, Morita K. 2007. Quantitative evaluation of the neuroprotective effects of thiopental sodium, propofol, and halothane on brain ischemia in the gerbil: effects of the anesthetics on ischemic depolarization and extracellular glutamate concentration. J Neurosurg Anesthesiol 19:171-178.

Lei H, Gruetter R. 2006. Effect of chronic hypoglycaemia on glucose concentration and glycogen content in rat brain: a localized ${ }^{13} \mathrm{C} N M R$ study. J Neurochem 99:260-268.

Lund-Andersen H. 1979. Transport of glucose from blood to brain. Physiol Rev 59:305-352.

Marszalec W, Narahashi T. 1993. Use-dependent pentobarbital block of kainate and quisqualate currents. Brain Res 608:7-15

Mather LE, Edwards SR, Duke CC, Cousins MJ. 2000. Microdialysis study of the blood-brain equilibration of thiopental enantiomers. $\mathrm{Br} \mathrm{J}$ Anaesth 84:67-73. 
Michenfelder JD. 2002. Positive experimental demonstration of the negative brain "protective" effects of anesthetics following cardiac arrest. Anesthesiology 97:1005-1006.

Mlynárik V, Gambarota G, Frenkel H, Gruetter R. 2006. Localized short-echo-time proton MR spectroscopy with full signal-intensity acquisition. Magn Reson Med 56:965-970.

Morris P, Bachelard H. 2003. Reflections on the application of ${ }^{13} \mathrm{C}$-MRS to research on brain metabolism. NMR Biomed 16:303312.

Pastuszko A, Wilson DF, Erecinska M. 1984. Amino acid neurotransmitters in the CNS: effect of thiopental. FEBS Lett 177:249-254.

Pfeuffer J, Tkáč I, Provencher SW, Gruetter R. 1999. Toward an in vivo neurochemical profile: quantification of 18 metabolites in short-echo-time ${ }^{1} \mathrm{H}$ NMR spectra of the rat brain. J Magn Reson 141:104-120.

Provencher SW. 1993. Estimation of metabolite concentrations from localized in vivo proton NMR spectra. Magn Reson Med 30:672-679.

Qu H, Faero E, Jorgensen P, Dale O, Gisvold SE, Unsgard G, Sonnewald U. 1999. Decreased glutamate metabolism in cultured astrocytes in the presence of thiopental. Biochem Pharmacol 58:1075-1080.

Rapoport SI, Hori M, Klatzo I. 1972. Testing of a hypothesis for osmotic opening of the blood-brain barrier. Am J Physiol 223:323331.

Singh SP, Srivenugopal KS, Yuan XH, Jiang F, Snyder AK. 1993. Effects of ethanol ingestion on glucose transporter-1 protein and mRNA levels in rat brain. Life Sci 53:1811-1819.

Sokoloff L, Reivich M, Kennedy C, Des Rosiers MH, Patlak CS, Pettigrew KD, Sakurada O, Shinohara M. 1977. The $\left[{ }^{14} \mathrm{C}\right]$ deoxyglucose method for the measurement of local cerebral glucose utilization: theory, procedure, and normal values in the conscious and anesthetized albino rat. J Neurochem 28:897-916.

Sood R, Taheri S, Estrada EY, Rosenberg GA. 2007. Quantitative evaluation of the effect of propylene glycol on BBB permeability. J Magn Reson Imaging 25:39-47.
Steen PA, Milde JH, Michenfelder JD. 1978. Cerebral metabolic and vascular effects of barbiturate therapy following complete global ischemia. J Neurochem 31:1317-1324.

Strang RH, Bachelard HS. 1973. Rates of cerebral glucose utilization in rats anaesthetized with phenobarbitone. J Neurochem 20:987-996.

Sutherland GR, Tyson RL, Auer RN. 2008. Truncation of the krebs cycle during hypoglycemic coma. Med Chem 4:379-385.

Swanson RA, Seid LL. 1998. Barbiturates impair astrocyte glutamate uptake. Glia 24:365-371.

Terpstra M, Andersen PM, Gruetter R. 1998. Localized eddy current compensation using quantitative field mapping. J Magn Reson 131:139-143.

Tkáč I, Starcuk Z, Choi IY, Gruetter R. 1999. In vivo ${ }^{1} \mathrm{H}$ NMR spectroscopy of rat brain at $1 \mathrm{~ms}$ echo time. Magn Reson Med 41:649656.

Tkáč I, Rao R, Georgieff MK, Gruetter R. 2003. Developmental and regional changes in the neurochemical profile of the rat brain determined by in vivo ${ }^{1} \mathrm{H}$ NMR spectroscopy. Magn Reson Med 50:24-32.

Tkáč I, Dubinsky JM, Keene CD, Gruetter R, Low WC. 2007. Neurochemical changes in Huntington R6/2 mouse striatum detected by in vivo ${ }^{1} \mathrm{H}$ NMR spectroscopy. J Neurochem 100:1397-1406.

Wechsler RL, Kleiss LM, Kety SS. 1950. The effects of intravenously administered aminophylline on cerebral circulation and metabolism in man. J Clin Invest 29:28-30.

Xu S, Yang J, Li CQ, Zhu W, Shen J. 2005. Metabolic alterations in focally activated primary somatosensory cortex of alpha-chloralose-anesthetized rats measured by ${ }^{1} \mathrm{H}$ MRS at 11.7 T. Neuroimage 28:401409.

Yatsu FM, Diamond I, Graziano C, Lindquist P. 1972. Experimental brain ischemia: protection from irreversible damage with a rapid-acting barbiturate (methohexital). Stroke 3:726-732.

Zhu XH, Du F, Zhang N, Zhang Y, Lei H, Zhang X, Qiao H, Ugurbil K, Chen W. 2009. Advanced in vivo heteronuclear MRS approaches for studying brain bioenergetics driven by mitochondria. Methods Mol Biol 489:317-357. 